\title{
Problems Facing Undergraduate Students At Al Ghad International College For Health Sciences: Basis To Improve Academic Performance
}

\author{
Paul Reinald Base Garcia, RN, MAN, MHA, PhD \\ Yasser Adnan Abu Jaish, RN, MSc, PhD \\ Al-Ghad International College for Health Sciences \\ Dammam, Male Campus \\ Kingdom of Saudi Arabia
}

doi: 10.19044/esj.2016.v12n22p281 URL:http://dx.doi.org/10.19044/esj.2016.v12n22p281

\begin{abstract}
This action research has sought answers to the following research questions: What are the problems encountered by the low performing students of different departments in terms of psychosocial, psychological and educational? What are the proposed specific measures geared towards the enhancement of learners' academic performance? Researchers have utilized a mixed method research design, both quantitative and qualitative methods which gave them greater confidence in establishing conclusion of the study. They have figured out specific measures to address problems in terms of psychosocial, psychological and education domains confronting the subjects of the study. These proposed measures are adaptation of academic performance flow chart and the revised attendance grading scheme. The authors also suggest the preparatory department to create an English proficiency committee which will design English proficiency programs for this low performing group zeroing in listening, reading, writing and speaking proficiencies. They also propose for the College to use better software management system and to conduct an annual departmental curriculum review and enhancement. They have included all of the students with GPA 2.75 and less from different departments of Al-Ghad International College Dammam Male Campus, a large and young private academic institution which offers various health care programs as participants of the study. A self-made questionnaire has been constructed and has become the main tool to gather the necessary data and interview has done to dissect the variables under scrutiny. Researchers have also used a standardized test (Kessler Psychological Distress Scale) which determined the psychological distress status of the subject learners. The gathered numeric data have been tabulated,
\end{abstract}


evaluated, analyzed and interpreted using Statistical Package for Social Science (SPSS) version 22.

Keywords: Academic Performance, Learners’ Problem, Low Performing Students

\section{Introduction}

The rapidly growing population estimated to be 31.6 million in 2016 of which 22.8 million will be Saudi nationals, a slowly aging society and the high occurrences of lifestyle disease create an increased demand on the health care resources. This situation is recognized by the government who has recently introduced initiatives to encourage the private sector to match the shortfall and benefit from this potentially lucrative sector (Colliers International, 2012). Building health care educational institutions such as medical and nursing colleges to increase the supply of medical professionals which would address the shortage of health care resources has been long realized. In this context, Al-Ghad International College for Health Sciences (AICHS), a young and fast growing private college with eight branches all over the Kingdom and one of the largest higher education institutions aims to continuously produce strong Saudi specialists expected to deliver professional standard of care across all health care settings.

AICHS, however, with the crucial thrust of providing quality health education for the young Saudi men and women through resilient classroom instruction, intense practical training and capacity building of administrative, academic and non-academic staff; is facing critical challenges particularly related to the growing number of low performing allied health care students who have been repeatedly failing courses in their respective health science discipline. The authors of this research have deemed necessary to assess the problems or challenges experienced by these allied health care learners which are considered as key components influencing their academic performance.

Further, student academic performance measurement has received considerable attention in many practical studies and considered as challenging aspects of academic literature, and student performance are affected due to social, psychological, economic, environmental and personal factors. These challenges strongly influence the student performance, but they vary from person to person and country to country (Mushtaq et.al., 2012). The researchers, on the other hand, have tried to assess specific causes of low academic performance in a particular non-performing group. In addition, identified causes from document review are categorized into three domains namely psychological, social and educational. Based on this 
impost, investigators of this study tried to craft academic enhancement measures certain for the distinctive individualities of these populations.

Moreover, learning enhancement strategies targeting these significant domains are important initiatives higher education institutes should embark on to back-up academic performance among these low performing learners. As cited in the study of Beauvais et. al. (2013) researchers have found that managing emotions is positively correlated with academic success (Ahammed, et.al., 2011) and (Mayer et. al, 2004). Other scholars have focused on how classroom techniques can promote psychological empowerment thus promoting academic success (Taliaferro, 2009).

On the other hand, College's Male Campus has been experiencing upsurge in student attrition rate. One of the factors considered is the high failing grade in various disciplines evidenced by grade analysis results. For instance, the Nursing Department has 53\% total failing grade in the theoretical courses and 16\% in the practical and laboratory last semester of school year 2014-2015. In addition, statistics divulge 40\% failing grades in major nursing courses such as Foundation of Nursing, Adult Health Nursing, Health Assessment, Pathophysiology, Psychiatric Nursing and Critical Care Nursing. Other discipline with low passing results are radiology department with 29\%, preparatory with 25\% and Emergency Medical Science (EMS) department, the largest in terms of student populace with $17 \%$ failing grade in both practical and theoretical sectors. These figures also imply that programs of choice of students from Preparatory level are the three (3) previously specified departments. Further this infers that the higher number of department populace, the higher failing rate is.

This figure has strongly cemented the need to conduct an investigation on the components affecting these low performing students' academic performance. The outcome of this inquiry has been represented by recommendations that the authors have deemed to implement.

\section{Findings and Discussion}

Collectively, the table below decodes that social and family factors are not problems experienced by the college's students with an overall weighted mean of 2.09 interpreted as disagree. On the contrary, two (2) out of fourteen (14) items appear significant which are: embarrassed to tell parents about personal problems and financial constraints of the family which affect studying with mean of 2.83 and 3.17 respectively with verbal interpretation of sometimes. It implies that family's socio economic status and the changing scholarship grant scheme of the government have negative impact on the learning process of some of the students. The result also signifies the college's role in bridging connections among its students and their parents. 
Table 1. Social and Family Problems

Social and Family Problems

Embarrassed to tell my parents personal problems

Conflicts between me and my colleagues in the college

Difficult to comply with traditions and culture Difficult to build relations with others Difficult to find a loyal friend

Experience parental fighting at home

Difficult to perform certain duties to my family

Parents sometimes interfere with my own affairs

Parents get angry when my friends visit me

\begin{tabular}{r|r} 
WM \\
2.83
\end{tabular}

WM

(1)

\begin{tabular}{c|c|c|} 
VI & $\mathrm{R}$ \\
Sometimes & 2
\end{tabular}

Pare

Parents don't deal with me in accordance to my
age

Parents overburden me with tasks at home which affect my study

Parents are authoritarian and don't allow me to give my opinion

Financial constraints of my family affect my study

Health problems of my family members influence my willingness to study seriously

\section{OVERALL WEIGHTED MEAN}

\begin{tabular}{l|l|l}
1.83 & Disagree & 10
\end{tabular}

$+2.0$

\begin{tabular}{|l|l|c|}
\hline 2.06 & Disagree & 7 \\
\hline 2.13 & Disagree & 4.5 \\
\hline 2.13 & Disagree & 4.5 \\
\hline 1.67 & Strongly & 13
\end{tabular}

2.13

\begin{tabular}{l|l|l} 
& Disagree & \\
2.12 & Disagree & 6 \\
\hline 2.02 & Disagree & 8
\end{tabular}

\begin{tabular}{l|l}
\hline & 2.12 \\
\hline & 2.02 \\
\hline & 1.62
\end{tabular}

Disagree

\begin{tabular}{l|l} 
Strongly & 14
\end{tabular}

1.78

Disagree

\begin{tabular}{|c|c|c|}
\hline 1.96 & $\begin{array}{c}\text { Disagree } \\
\text { Disagree }\end{array}$ & 9 \\
\hline 3.17 & $\begin{array}{c}\text { Strongly } \\
\text { Disagree }\end{array}$ & 12 \\
\hline 2.27 & Dometimes & 1 \\
\hline 2.09 & \multicolumn{2}{|c|}{ DISAGREE } \\
\hline
\end{tabular}

Sis

\begin{tabular}{l|l} 
Strongly & 11 \\
Disagree &
\end{tabular}

The lowest rankings, however; are: parents get angry when friends visit (1.62 WM), experience parental fighting at home (1.67 WM) and parents are authoritarian and don't allow giving opinion (1.72 WM); all with interpretation of strongly disagree. These figures imply strong family ties and openness to communication which can be considered as opportunity to create strong collaboration between the college and family aiming at students' academic welfare.

Table 2. Psychological Problems

\begin{tabular}{c|c|c|c}
\multicolumn{2}{c}{ Psychological Problems } & WM & VI \\
\hline $\begin{array}{c}\text { Hesitate in making decisions to solve personal } \\
\text { problems }\end{array}$ & 2.89 & Sometimes & 4 \\
\hline Difficult to focus on my study due to my problems & 2.90 & Sometimes & 3 \\
\hline Get angry when I face difficulties & 2.99 & Sometimes & 2 \\
\hline Give up to my desires easily & 2.48 & Disagree & 7 \\
\hline Feel shy when I talk to anyone older than me & 2.70 & Sometimes & 5 \\
\hline Feel that my self-confidence is weak & 2.13 & Disagree & 12 \\
\hline Suffer from terrible night dreams & 2.05 & Disagree & 13 \\
\hline Usually feel that I am moody & 2.40 & Disagree & 8 \\
\hline Feel that I am not always accountable of my actions & 2.34 & Disagree & 9 \\
\hline
\end{tabular}




\begin{tabular}{|c|c|c|c|}
\hline Easily get angry when others provoke me & 2.68 & Sometimes & 6 \\
\hline Feel withdrawn and isolate myself from others & 1.99 & Disagree & 14 \\
\hline Usually think of committing suicide & 1.52 & $\begin{array}{l}\text { Strongly } \\
\text { Disagree }\end{array}$ & 15 \\
\hline Emotions can easily be affected by my friends & 2.21 & $\begin{array}{l}\text { Strongly } \\
\text { Disagree }\end{array}$ & 11 \\
\hline $\begin{array}{l}\text { Afraid of and anxious about future and the } \\
\text { unknown }\end{array}$ & 3.15 & Sometimes & 1 \\
\hline $\begin{array}{l}\text { Often feel sick which affect my focus in the } \\
\text { classroom }\end{array}$ & 2.32 & Disagree & 10 \\
\hline OVERALL WEIGHTED MEAN & 2.36 & \multicolumn{2}{|c|}{ DISAGREE } \\
\hline
\end{tabular}

Similar to the previous table, generally, psychological factors are not considered as problems affecting academic performance as perceived by the participants, evidenced by overall weighted mean of 2.36 or disagree. On the other hand, many items show remarkable result: afraid and anxious about future and the unknown (3.15 WM), get angry when facing difficulties (2.99 WM), and difficulty on focusing on the study when problems are encountered (2.90 WM). These items are followed by hesitation in making decisions to solve personal problems (2.89 WM), feeling shy to talk with anyone older ( $2.70 \mathrm{WM})$, and lastly easily get angry when provoked by someone else. The data imply for an intensive academic counseling measures layering not only the academic issues but also personal and psychological concerns. It signifies the need to educate learners about stress and anger management to be done not only by academic counselors but also by experts in adolescent or young adult psychology.

Among the least ranking items are thinking of suicide (1.52) as strongly disagree, feeling withdrawn and isolating oneself (1.99) and suffering from terrible night dreams (2.05) both with verbal interpretation of disagree.

Table 3. Kessler Psychological Distress Scale

Kessler Psychological Distress Scale $\quad$ WM

\begin{tabular}{c|c|c|c|}
\hline feel tired out for no good reason & 2.60 & Sometimes & 2 \\
\hline Feel nervous & 2.50 & Little Time & 3 \\
\hline Feel nervous that nothing can calm me & 2.00 & Little Time & 9 \\
\hline Feel hopeless & 2.46 & Little Time & 4 \\
\hline Feel restless or fidgety & 2.66 & Sometimes & 1 \\
\hline Feel restless I couldn’t sit still & 2.37 & Little Time & 6 \\
\hline Feel depressed & 2.26 & Little Time & 7 \\
\hline Feel everything is an effort & 2.45 & Little Time & 5 \\
\hline Feel sad that nothing can cheer me up & 2.22 & Little Time & 8 \\
\hline Often feel worthless & 1.84 & Little Time & 10 \\
\hline OVERALL AVERAGE & 23.37 & \multicolumn{2}{|c}{ MILD MENTAL } \\
\hline
\end{tabular}


Legend: <20 - Normal; 20 - 24 - Mild Mental Disorder; 25 - 29 - Moderate Mental Disorder; 30 - Severe Mental Disorder

In line with the psychological problems, the researchers have tried to assess the psychological distress scale using standardized tool as shown in the table above. Collectively, scores reveal that low performing students are experiencing mild mental disorder with an overall average score of 23.37. According to Joint Commissioning Panel for Mental Health (JCPMH) mild to moderate mental problems can be at regular occurrence depending on the emotional well-being of a person which fluctuates from day to day. However, these findings disclose the need for interventions to improve mental health and well-being of learners.

Among the identified variables under investigation, educational factors are considered significant problems perceived by low performing students with overall mean of 3.01 or verbal interpretation of sometimes shown in Table 4 . The highest rankings as presented in the table are disappointed with low GPA (4.22 WM), strongly agree; learn several new things from the practical training (3.89 WM), and learn several new things from the theoretical teaching $(3.40 \mathrm{WM})$ both with interpretation of agree. It implies the continuous improvement on teaching standards and attainment of learning outcomes for various courses.

In addition, among the items participants have agreed on are: unsatisfied with the limited availability of college's co-curricular activities (3.52), feeling upset that some lecturers are non-specialist to teach the specialty courses and suffering from lengthy lectures of the courses in accordance to the lecture time, both with mean of 3.48. These data indicate the need to develop more college activities which would create an avenue for student participation as well improvement of the colleges' recreational facilities. The results likewise reveal weaknesses in faculty recruitment and placement, however, an opportunity to develop expert educators through workshops, seminars and other non-formal education in line with the courses they teach. Continuous workshops on teaching strategies and other similar trainings are also evidently essential as they have perceived having difficulty in understanding some of the courses (3.45 WM), agree; and some of the lecturers use the traditional method of teaching (2.90 WM) interpreted as sometimes.

Table 4. Educational Problems

\begin{tabular}{c|c|c|c|}
\hline \multicolumn{2}{c}{ Educational Problems } & WM & RI \\
\hline $\begin{array}{c}\text { Not satisfied with the limited availability of college's } \\
\text { co-curricular activities }\end{array}$ & 3.52 & 4 \\
\hline Face problems to understand some of the courses & 3.45 & Agree & 7 \\
\hline Feel upset with the impoliteness of lecturers when & 2.96 & Sometimes & 17.5 \\
\hline
\end{tabular}




\begin{tabular}{|c|c|c|c|}
\hline dealing with students & & & \\
\hline $\begin{array}{l}\text { Difficult for me to register courses at the beginning of } \\
\text { the semester }\end{array}$ & 2.96 & Sometimes & 17.5 \\
\hline Difficulty to organize the time to attend the lectures & 2.67 & Sometimes & 24 \\
\hline Find difficulty to understand the daily lectures & 2.72 & Sometimes & 21 \\
\hline $\begin{array}{c}\text { Suffer from the congestion of the students in the } \\
\text { classroom }\end{array}$ & 2.66 & Sometimes & 26 \\
\hline $\begin{array}{l}\text { Feel disappointed with lack of opportunities to meet } \\
\text { the lecturer who would supposedly help me in dealing } \\
\text { with my problems }\end{array}$ & 2.65 & Sometimes & 27 \\
\hline Feel disappointed with low GPA & 4.22 & $\begin{array}{l}\text { Strongly } \\
\text { Agree }\end{array}$ & 1 \\
\hline $\begin{array}{l}\text { Feel upset that some lecturers are non-specialist to } \\
\text { teach the specialty courses }\end{array}$ & 3.48 & Agree & 5.5 \\
\hline $\begin{array}{l}\text { Feel disappointed the academic advisor fails in } \\
\text { fulfilling his duties }\end{array}$ & 2.67 & Sometimes & 24 \\
\hline $\begin{array}{l}\text { Bothered with strict disciplinary rules and punctuality } \\
\text { implemented by the lecturers }\end{array}$ & 2.29 & Disagree & 31 \\
\hline Don't have suitable atmosphere to study at home & 2.38 & Disagree & 29 \\
\hline $\begin{array}{l}\text { Some of the lecturers use the traditional methods of } \\
\text { teaching }\end{array}$ & 2.90 & Sometimes & 19 \\
\hline $\begin{array}{l}\text { Suffer from lengthy lectures of the courses in } \\
\text { accordance to the lecture time }\end{array}$ & 3.48 & Agree & 5.5 \\
\hline $\begin{array}{c}\text { Suffer from no unified content of lectures in the } \\
\text { department }\end{array}$ & 3.07 & Sometimes & 14 \\
\hline $\begin{array}{l}\text { Learning outcomes of the courses would not meet my } \\
\text { goals and desires }\end{array}$ & 2.46 & Disagree & 28 \\
\hline $\begin{array}{l}\text { Upset because some students get high grades despite } \\
\text { failing to attend some lectures }\end{array}$ & 3.15 & Sometimes & 12 \\
\hline Consider education in negative way & 2.26 & Disagree & 32 \\
\hline $\begin{array}{l}\text { Feel upset when I do not receive the course syllabus at } \\
\text { the beginning of the semester }\end{array}$ & 2.67 & Sometimes & 24 \\
\hline $\begin{array}{l}\text { Feel annoyed with the tardiness of the lecturer in the } \\
\text { classroom and in consistent classroom management }\end{array}$ & 2.30 & Disagree & 30 \\
\hline $\begin{array}{c}\text { Feel overwork due to numerous assignments or course } \\
\text { requirements from the lecturers }\end{array}$ & 3.07 & Sometimes & 14 \\
\hline $\begin{array}{l}\text { Feel upset when I don't receive the course content at } \\
\text { the beginning of the semester }\end{array}$ & 2.70 & Sometimes & 22 \\
\hline $\begin{array}{l}\text { Feel upset when I don't receive the handout 2-3 days } \\
\text { before the lecture }\end{array}$ & 3.61 & Agree & 3 \\
\hline $\begin{array}{l}\text { Find difficulty to study on the course which doesn't } \\
\text { interest me }\end{array}$ & 3.23 & Sometimes & 11 \\
\hline Find difficulty in understanding what I read & 2.77 & Sometimes & 20 \\
\hline $\begin{array}{l}\text { Find difficulty in tracking down answers to my } \\
\text { questions in the class }\end{array}$ & 2.99 & Sometimes & 16 \\
\hline $\begin{array}{l}\text { Better to stick with the learning methods that we know } \\
\text { instead of always trying new ones }\end{array}$ & 3.07 & Sometimes & 14 \\
\hline Learn several new things from the theoretical teaching & 3.40 & Agree & 8 \\
\hline Learn several new things from the practical training & 3.89 & Agree & 2 \\
\hline
\end{tabular}




\begin{tabular}{c|c|c|c|}
\hline $\begin{array}{c}\text { Difficulty in reading and understanding exam } \\
\text { questions }\end{array}$ & 3.39 & Sometimes & 9 \\
\hline $\begin{array}{c}\text { Most of the items in the exam are difficult to } \\
\text { understand and answer }\end{array}$ & 3.35 & Sometimes & 10 \\
\hline Overall Weighted Mean & 3.01 & \multicolumn{2}{|c|}{ Sometimes } \\
\hline
\end{tabular}

Participants have sighted that sometimes they find it difficult to read and understand exam questions and most of the items in the exam are difficult to understand with weighted mean of 3.39 and 3.35 respectively. These results manifest low English proficiency by learners supported by the item finding difficulty to understand daily lecture, 2.72 and finding difficulty in understanding what has been read, 2.77. These findings imply two important things: to review test construction and lecture construction proficiency of faculty and to design an intensive English proficiency program by the college.

Teacher factors have always been an issue such as failing to receive handouts 2-3 days before the lecture (3.61), agree; failing to receive course content at the beginning of the semester (2.70), failing to receive course syllabus at the beginning of semester (2.67); and feeling overwork due to numerous assignments or course requirements from the lecturers (2.30) with all interpreted as sometimes. These have been considered as implications of lack of software management system where the lectures and other learning materials can be downloaded. The latter however, implies the need to connect learning objectives with course requirements and assignments, then to be clearly communicated among learners. Other teacher factors which warrant attention are feeling upset with the impoliteness of lecturers when dealing with students, (2.96) and lack of opportunities to meet the lecturer during office hours, (2.65) both inferred as sometimes. They denote the need to improve the culture of student - centered academic environment.

On the contrary, student factors are also considered as issues confronting allied medical learners. These are difficulty studying the course which doesn't interest them, (3.23); difficulty in tracking down answers to questions in the class, (2.99); and the perceived idea of sticking to the learning methods they know instead of always trying new ones, (3.07); all with interpretation of sometimes. The outcomes suggest the need to intensify motivation strategies which would regenerate course interest. These also signify use of teaching strategies which might deepen independent learning skills and expand the understanding of the importance of various learning methods.

Further, another student factor is difficulty in organizing time to attend lectures with a mean of (2.67), interpreted sometimes. This implies the essentiality to incorporate time management and good study habits in the academic counseling sessions. Contrary, items such as feeling disappointed 
that academic advisor fails in fulfilling his duties obtain (2.67) mean interpreted as sometimes. This leaves a strong message to review academic counseling program and create a flow chart in order to streamline the academic counseling procedures.

Other educational factors which sometimes affect learners are difficulty in registering courses at the beginning of the semester (2.96); suffering from non-unified content of lectures in the department (3.07); and feeling upset because some students get high grades despite failing to attend some lectures (3.15); all with interpretation of sometimes. The results indicate the need to review, enhance and streamline the process of student registration, create course committee for male and female campuses intended to craft single and enhance educational materials and assessment tools. The latter item, however, suggest to review and modify the attendance grading system if found bias.

\section{Conclusion}

Collectively, family, social and psychological problems are not considered as perceived factors affecting low performing students in their studies. However, some items appear significant such as: they feel afraid and anxious about the unknown, getting angry when facing difficulty and have difficulty in focusing on studies when problems confront them. In addition, Kessler Psychological Distress scores reveal that they are experiencing mild mental disorder which is considered as common among individuals facing difficulties. This necessitates profound guidance counseling from academicians who have expertise in young adult psychology. Further, this investigation reveals a culture of strong family values which can be exploited by the College to inculcate resilient study behavior among them.

Contrary to the two aforementioned variables, educational problems categorized into teacher, learner and college factors are considered as problems confronting learners under scrutiny. In the domain of teacher factors, non-specialist lecturers, lengthy lectures, failing to give lecture handouts 2-3 days before lecture time, failing to receive course syllabus at the beginning of the semester, bulk of course requirements, impoliteness of lecturers when dealing with them and lack of opportunities to meet the lecturer during office hours are problems encountered by learners. The student factors are lack of study habits especially on the course which do not interest them, insufficient research skills in tracking down answer to their queries, and low English proficiency since they have difficulty understanding daily lecture, the readings they have made and difficulty understanding exam questions. Another significant finding is the difficulty of the respondents to organize time in attending lectures. 
Lastly, the perceived problems in the context of college factors are limited co-curricular activities, difficulty on the course registration during the beginning of the semester, colleges' grading scheme particularly on the attendance grade and non-unified lectures in each department.

\section{Recommendation}

The college should intensify academic counseling by creating a clear academic performance monitoring for all the students giving additional emphasis on low performing learners. There should be a sturdy collaboration between the college's administrators and parents of the learners. Parents should be well informed of the students' academic status and college's initiatives in helping these students in attaining their academic goal. An academic counseling flow chart should be created to guide the faculty, academic counselors and department head on the protocol of academic counseling. In this context, the authors of this investigation have created the propose flow chart as shown in figure 1 . The said diagram represents the algorithm the (3) departments which are nursing, EMS and MIT with the highest student failing rate should partake in enlisting students in health care programs. This illustrates various solutions to the college problems.

In the diagrammatic representation, screening criteria such as interview, aptitude test and GPA review should be made among students from the preparatory program and transfer students. These are bases for the department head to accept students in the program or otherwise refer them to other program offerings of the college. This will warrant students' capacity to succeed in the rigid undertakings among the three (3) most difficult programs. The subsequent phase of the scheme is registration to be facilitated by the department head and faculties who will also be the academic counselors of newly accepted level (3) students. Assigned academic counselors should be teaching the major courses of the said level and they should also give initial explanation of the courses offerings and course assessment scheme and requirements. Further a general orientation should be made spearhead by the department head. Department policies including retention policies and the entire course program should be clearly cascaded among the learners. 
Figure 1. Proposed Academic Performance Flow Chart

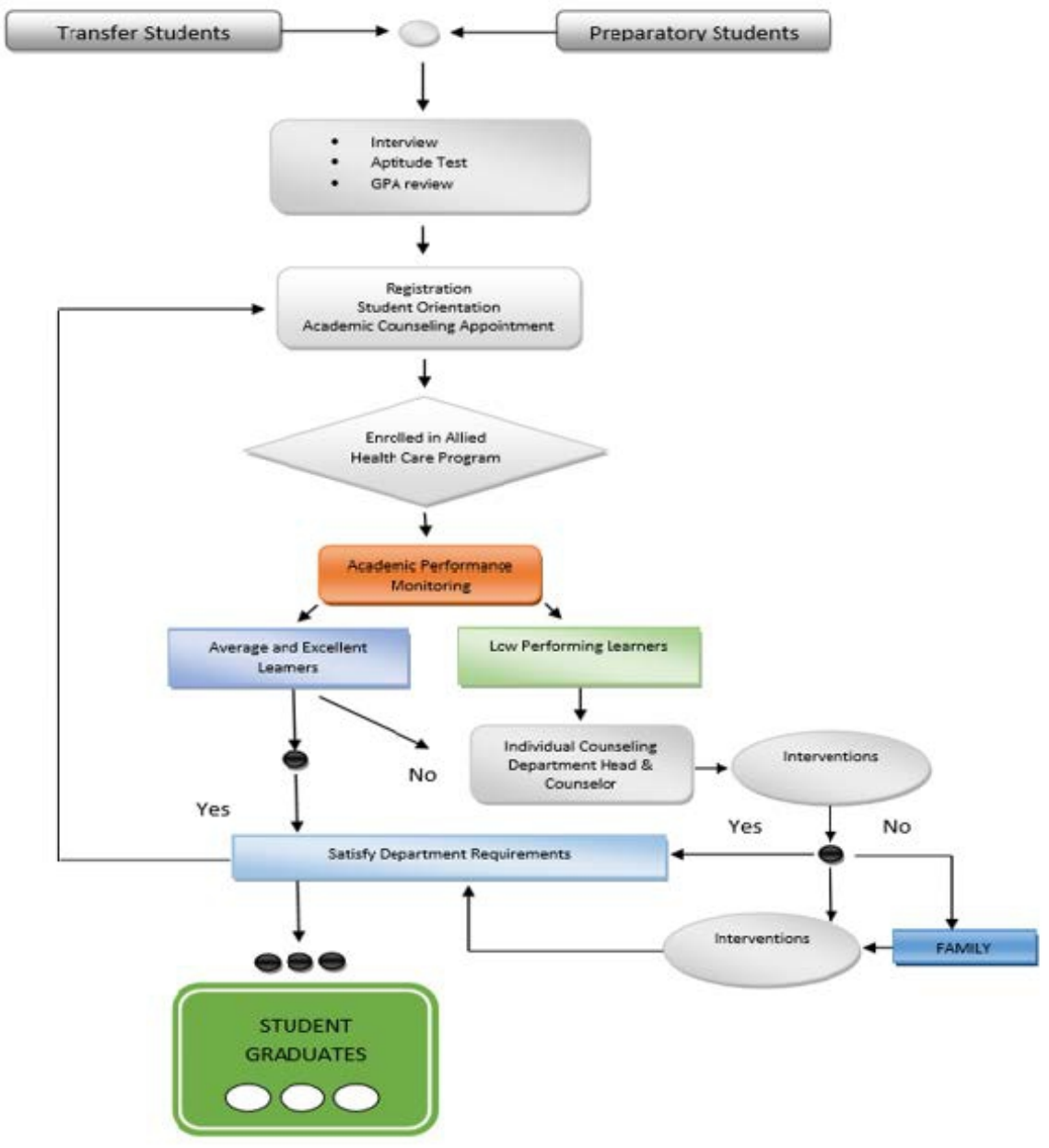

During the course semester, strict monitoring of their academic performance should be completed by each lecturer and clinical instructors. An academic monitoring form should be used as communication tool between them and academic counselors with suggested interventions. The quality unit should create a standardized tool applicable to all the departments of the college. This important instrument would provide the academic counselors and the student themselves on the areas of weakness which needs to be addressed. This is the starting point of intrusions on the chain of failing.

An English proficiency committee should be created by the preparatory department and they should design an English proficiency program enhancement measures for the identified low performing students geared towards the improvement of reading, writing, listening and speaking abilities. Further, there should be guidance and counseling on time 
management, stress management and good study habits among the learners and constant motivation should be accomplished. There is also a need to hire an expert on young adult psychology who will provide advising on personal and academic problems experience by the learners especially those who are low performing.

The college should adapt a flexible learning environment like Moodle which is designed to support face-to-face teaching with wide range of versatile online tools as well as providing a place to upload resources for courses. Lecturers and clinical instructors should upload their teaching tools and presentation 3 days prior to their class.

Figure 2. Proposed Revised Grading Scheme

\begin{tabular}{|c|c|c|c|c|c|c|}
\hline \multicolumn{7}{|c|}{ Grading Scheme } \\
\hline $\begin{array}{c}\text { Number of } \\
\text { Absence }\end{array}$ & 5 Absent & 4 Absent & 3 Absent & 2 Absent & 1 Absent & 0 Absent \\
\hline Marks & 0 & 1 & 2 & 3 & 4 & 5 \\
\hline $\begin{array}{c}\text { Percentage of } \\
\text { Absence }\end{array}$ & & $25 \%$ & $20 \%$ & $10 \%$ & & Full Mark \\
\hline Interventions & $\begin{array}{l}\text { Failed the } \\
\text { Course }\end{array}$ & $\begin{array}{l}\quad 3^{\text {d }} \text { Written } \\
\quad \text { Warning } \\
\text { - Academic } \\
\text { counselor notify } \\
\text { the student and } \\
\text { department head } \\
\text { - Notify the } \\
\text { academic } \\
\text { counseling } \\
\text { committee and } \\
\text { psychologist } \\
\text { - Interventions by } \\
\text { the committee } \\
\text { and psychologist } \\
\text { - Notify the } \\
\text { parents regarding } \\
\text { absenteeism }\end{array}$ & \begin{tabular}{l}
\multicolumn{1}{c}{$2^{\text {wd }}$ Written } \\
Warning \\
- Academic \\
counselor notify \\
the student and \\
department head \\
- Notify the \\
academic \\
counseling \\
committee and \\
psychologist \\
- Interventions by \\
the committee \\
and psychologist \\
- Notify the \\
parents regarding \\
absenteeism
\end{tabular} & $\begin{array}{l}\text { 1" Written } \\
\text { Warning } \\
\text { - Academic } \\
\text { counselor notify } \\
\text { the student and } \\
\text { department head }\end{array}$ & $\begin{array}{l}\text { Verbal Warning } \\
\text { - Academic } \\
\text { counselor notify } \\
\text { the student }\end{array}$ & \\
\hline
\end{tabular}

In the context of grading system, authors of this study recommend the implementation of the revised attendance grading scheme stipulated in figure 2. Students are required to attend 11 out of 15 weeks of class in a semester. Five (5) absences without valid reasons and supporting documents automatically put the students in a failing status and are given a mark of (0). Four (4) absences however, which is equivalent to $25 \%$ absence would warrant the students to receive $2^{\text {nd }}$ warning form. Academic counselor should endorse students who receive second warning to the academic counseling committee headed by college psychologist for interventions. They need also to inform parents regarding the attendance status of the student. A grade of (1) would be given to the student. For (3) absences, same interventions would be done except for the giving of marks which is (2). A mark of (3) will be given to those who would incur ( 2 absences) and they will receive the $1^{\text {st }}$ warning. This is $10 \%$ absent on the academic semester. On the other hand, verbal warning by academic counselor and a grade of (4) should be given to the student in case of 1 absent. The new attendance grading protocol should 
be clearly communicated to the student and deemed to reduce the absenteeism among them in addition to the perspective of grade equity.

Curriculum review and enhancement should also be annually done to ensure that the lecture and classroom and field practice coincides with each other in terms of delivering content topics and to remove obsolete concepts and add needed course topics. There should be course committee between the two campuses (male and female) to create standard learning resources to be uploaded in the college's management system. Objective Structured Clinical Examination (OSCE) should be implemented among all the major courses of the department. This will intensify acquisition of competence among basic and advance skills and would strongly build connections between theory and practice.

\section{References:}

Ahammed S., Abdullah A., Hassane S. (2011). 'The Role of Emotional Intelligence in the Academic Success of United Arab Emirates University Students.' International Education: Vol. 41 No. 1.

Beauvais Audrey, Stewart Julie, De Nisco Susan \& Beauvais John. (7 December 2013). 'Factors related to Academic Success Among Nursing Students: A Descriptive Correlational Research Study'. Nurse Education Today: Vol. 34 No. 6

http://dx.doi.org/10.1016/j.nedt.2013.12.005

Irfan Mushtaq \& Shabana Nawaz Khan Mohammad Ali Jinnah University Islamabad, Pakistan. (12 June 2012). 'Factors Affecting Students' Academic Performance'. Global Journal of Management and Business Research: Vol.12 No.9.

https://globaljournals.org/GJMBR_Volume12/3-Factors-Affecting-StudentsAcademic.pdf

Joint Commission Panel for Mental Health. How common are mild to moderate mental health problems. Retrieved from: http://www.jcpmh.info/commissioning-tools/cases-for-change/mild-tomoderate-problems/how-common/

Kessler, R.C., Andrews, G., Colpe, .et al (2002) Short screening scales to monitor population prevalences and trends in non-specific psychological distress. Psychological Medicine, 32, 959-956.

Kingdom of Saudi Arabia Health Care Overview, Colliers International, 2012.https://C:/Users/Dr.\%20Paul\%20Garcia/Downloads/Collier\%20Study. pdf Mayer,J.D., Salovey, P., Caruso, D., (2004). 'Emotional intelligence: theory, findings, and implications.' Psychol. Inq: Vol 15 No. 3.

Taliaferro, L.A., Rienzo, B.A., Pigg, R.M., Miller, M.D., Dodd, V.J., (2009). Spiritual Well-being and Suicidal Ideation Among College Students. J. Am. Coll. Heal. Vol 58 No.1. 